\title{
System Design of Management of Energy Resources in the Field of
} Housing

\author{
${ }^{1}$ Alexey G. Isavnin, ${ }^{2}$ Denis M. Lysanov, ${ }^{3}$ Irina I. Eremina, ${ }^{4}$ Izida I. Ishmuradova, ${ }^{5}$ Anton N. Karamyshev \\ ${ }^{1-5}$ Kazan Federal University \\ Email: IIIshmuradova@kpfu.ru
}

Received: 23 ${ }^{\text {rd }}$ July 2019, Accepted: 10 $^{\text {th }}$ August 2019, Published: $31^{\text {st }}$ August 2019

\begin{abstract}
The main areas of work connected with improvement of the sphere of housing are development of the regulating, managing configurations of the equipment, change parameters of real-time operation, remote data collection from metering devices, adjustment of volumes of the provided utilities. It will allow to improve monitoring of functioning of a data collection system about the received utilities and to increase efficiency of identification of power losses in system.

Automatic data acquisition from the metering devices of water and the electric power transferred directly to financial settlements center will allow to reduce influence on them of a human factor, to exclude errors at removal and information transfer.
\end{abstract}

\section{Keywords}

Housing, Energy Resources, Managing Configuration, Data Collection, Accounting Automation.

\section{Introduction}

Housing is the largest sphere of economy and plays an important role in providing normal conditions of existence of people.

Today, energy saving - one of the major tasks connected with all social and economic aspects of development of society including questions of environmental protection. Considerable reserves of conservation of energy are in water supply systems and heat supplies of buildings as about $40 \%$ of the extracted fuel are spent for heat generation.

Housing causes an originality and specifics of its activity which is extremely many-sided. Monopolism existence; the high social importance and the vital kind of work in the housing sphere; local nature of production and consumption of works and services; the high level of complexity of this sphere that is expressed in need to simultaneous coordination of functioning of the housing organizations in a uniform technology chain with other enterprises of public service - here not the complete list of specifics and features of the housing sphere which need to be considered when forming effective approach to management.

The housing sphere is among the industries in which social, economic and political problems of society most sharply faced. The interrelation between level of income of the population, existence of well-planned housing and quality of life of the population is among.

The problem of heat supply of residential areas consists in providing each inhabitant with heating of its apartment at the comfortable level, uninterrupted supply of hot water of proper temperature and quality, at the same time conditions on payment of this service in that volume in which it consumed it have to be created. These tasks have to be performed at the minimum costs of means and with use of modern technical solutions [7].

\section{Methods and Models}

For automation of accounting of consumption of energy resources it is necessary to install pulse counters which principle of work same, as well as at normal mechanical counters: water untwists the impeller, turnovers from the impeller are counted and transferred to the dial. Each turnover of an arrow counts the fixed water volume - one turnover of an arrow is equal to $0.01 \mathrm{CBM}(10 \mathrm{l})$. For the end of an arrow the magnet and when the arrow makes revolution fastens, as a result of interaction with a magnet the impulse which is transferred on a wire line in the calculator of an expense or the counter is created. Further the impulse can be transferred on inter-chip digital links in network of a system of accounting of an expense of energy carriers or on the Internet. The benefit of such counters consists in convenience of treatment of them, simplicity of installation, lack of need of an electric power supply relative low cost and reliability.

System of installation of such counters following: at first the system of abnormal overlapping of water which blocks water automatically that will allow to make water supply shutdowns to debtors is mounted. For management the controller working from the rechargeable battery in the existing connector is put the radio station is connected, pulse counters join the separate drive of data, the GSM module for transfer of collected data from counters of water, the electric power is installed (fig.). 


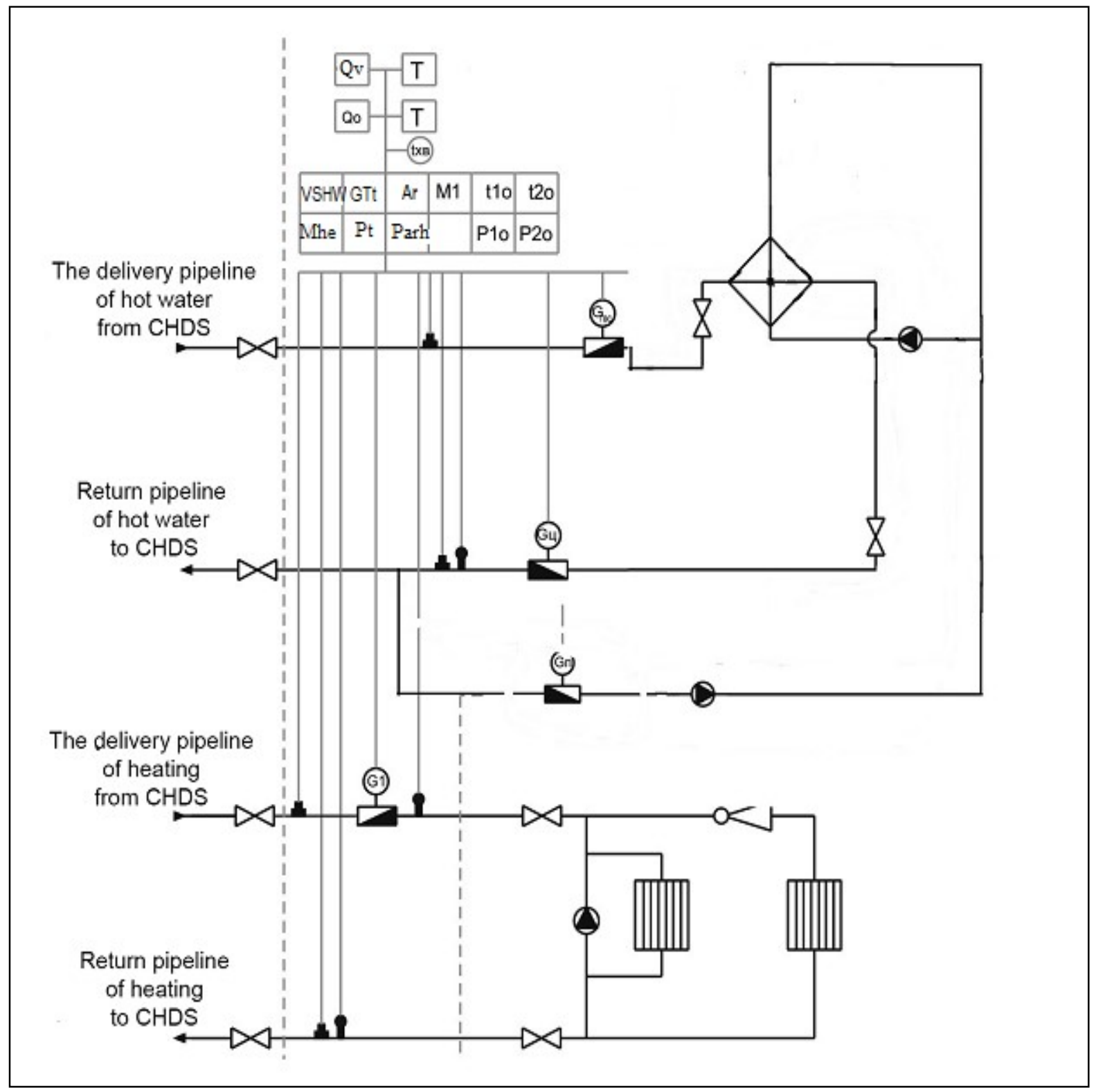

Figure 1: Installation Diagram of Metering Devices of Consumption of Energy Resources:

CHDS - Central Heat Distribution Station, VSHW - the volume of supply of hot water from the route, GTt - giving temperature in a trass, Ar adjustment according to regulations, M1 - the current return of water from the house, t1o - temperature after adjustment in the giving pipeline, t2o temperature on the return pipeline of hot water supply, Qv - the water volume consumed by the house for the entire period, Qo - the gigacalories consumed on heating, $\mathrm{T}-$ average temperature, Mhe - the total amount of the come heat energy, $\mathrm{Pt}-$ pressure in a trass, Parh - pressure on adjustment regulation for the house, $\mathrm{P} 1 \mathrm{o}$ - pressure after adjustment on giving, $\mathrm{P} 2 \mathrm{o}$ - returnable pressure after passing of a cycle.

The automated removal of data is performed without access to the apartment. Volumes of consumption and possible faults of the equipment are specified in the data obtained from the apartment. Such scheme of work will reduce unallotted volumes of water that will help to save money, will increase quality of the provided services, will also allow to exclude an excessive expense and will lower a payment for housing services, work with debtors will become simpler. If there is an intervention in operation of the counter, data will be reflected at collection of information. For intervention in operation of the counter exacting measures will be applied to the owner, and at failure of the metering device he will need to compensate equipment cost completely.

The system of collecting, the analysis and data management includes the following principal components (fig.) [6, 8]: 


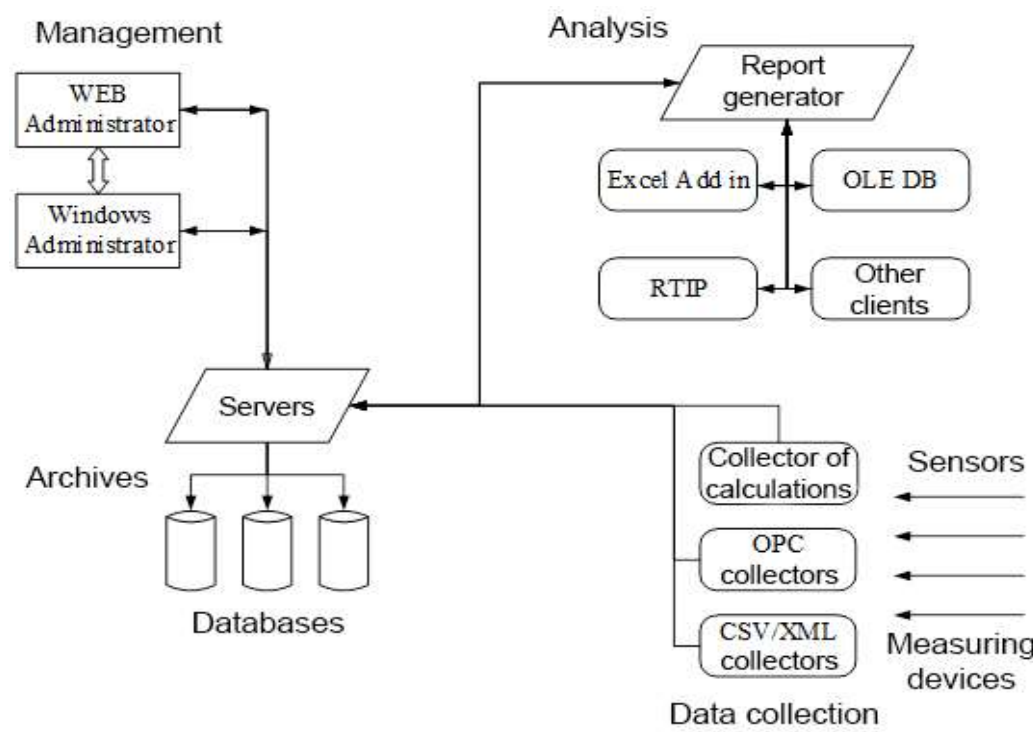

Figure 2: Scheme of a Data Management System

RTIP - the interactive processor of the peripheral terminal. Helps to collect data from different devices and to create the general reporting. Excel - these Excel programs. Tables, calculations, charts, the structure of accounting and calculation created earlier.

OLE DB - the technology allowing applications is unified to work with data from different sources and information warehouses, separates the data storage from the application.

OPC collectors - the program of accumulation and data formatting for the program of management and its further analysis.

CSV/XML - The XML format represents a rule set for coding of documents in a machine format. CSV represents a file format for storage of tabular data in the form of the plain text.

\section{Results and Discussion}

The collector of calculations - accumulates numerical indicators and creates of them the necessary reporting. It is possible to use several different configurations of management systems [9]:

1. The system is organized and configured on the normal computer. In that case on the controller the server of data and the Web server, and on the computer - the web browser is located. It is optional to use the computer to information display, it is possible to use any device on which the web browser is started and there is an access to the controller on network.

2. A basis of system is the server of data which remains in the controller, the Web server is located on the computer or in a cloud. Its role can execute the personal computer, and the display system with the web browser is installed on any other computer, the tablet or phone.

3. The Web server and the server of data are located on one computer or on a cloud server that allows to construct management system not only for several local controllers, but also for the controllers located on considerable removal from each other (fig).

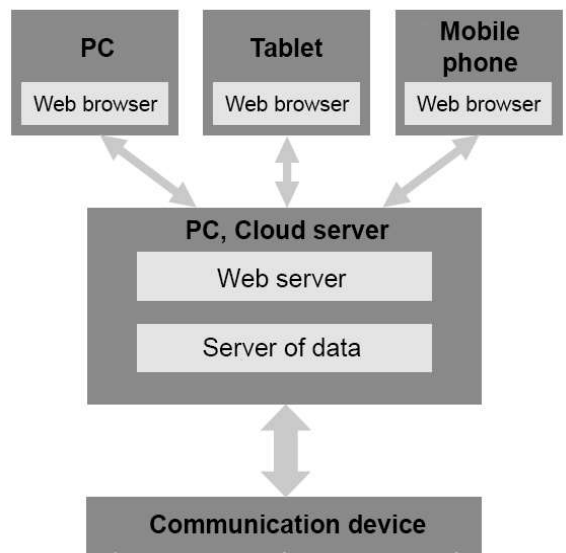

Figure 3: System Configuration of Management

One-time purchase of the software of electronic accounting for installation on the notebook or the computer will cost approximately 20 thousand rubles for the one-room apartment. If the apartment of two, three-room, the cost of the equipment a little increases [10]. 


\section{Summary}

On average the contract organization will save up to 500 thousand rubles from own expenses connected with liquidation of debt to service providers. For several years it is possible to pay back completely implementation of such management system, and the rest of the raised funds to aim the enterprises at the development.

Installation and use of system has the following features:

1) At a stage of implementation considerable costs, especially for old housing stock are required. Implementation of such management system is relevant for new buildings as the cost of installation of system will be included apartments in the price. After construction of a house with such system all necessary documentation, information base and the technical documentation are transferred to management company and contract organizations which will service all devices.

2) No arrangements with residents on removal of data from metering devices are required - all necessary data can be unloaded through the special program that increases reliability of these metering devices.

3) Work with debtors on payment becomes simpler - the instruction by mail goes, the call by phone is made. If no reaction followed, necessary documents are brought to trial. If it is required, perhaps remote cutoff of water in the apartment.

For creation of a managing configuration the software environment of SCADA having rather big feature set is used. Thanks to the built-in configured Web server, each user can use only those functions which are necessary in its work.

SCADA system solve the following problems [1, 3]:

- Data exchange with industrial controllers and payments of input-output in real time.

- Information processing in real time.

- Logical management.

- Information display on the monitor screen in a form, convenient and clear for the person.

- Database maintenance of real time with technology information.

- Alarm signaling and management of disturbing messages.

- Preparation and generation of reports on the course of technology process.

- Implementation of network interaction between computers.

- Ensuring communication with external applications (DBMS, electronic spreadsheets, word-processors,

etc.).

SCADA system usually contains the following subsystems [4, 5]:

- Drivers or servers of input-output - the programs providing communication of SCADA with industrial controllers, counters, and other input/output devices of information.

- Real-time system - the program providing data processing within the set temporary cycle taking into account priorities.

- The human-computer interface - the tool which submits data on the process course to the operator that allows to control process and to manage it.

- The system of logical management - the program providing execution of the user programs (scripts) of logical management.

- The database of real time - the program providing process history logging in real time.

- Management system alarms - the program providing automatic control of technology events, their reference to category normal, warning or abnormal and also event handling by the operator or the computer.

- The report generator - the program providing creation of the user reports on technology events.

- External interfaces - standard data exchange interfaces between system and other applications (DDE, ODBC, DLL, etc.).

In SCADA there are programming modules, for creation of configurations of remote control of different industrial devices. This equipment works in real time, where on each installed sensor it is visible that occurs at the moment and allows to react quickly to unusual situations and to perform regulation of parameters of devices separately and systems in general [2].

Through the program connection at the same time from 1000 control objects is possible that is important at management of housing stock. Range of communication of the block in a radius of $5 \mathrm{~km}$ from the computer host from which commands on regulation are transferred. For increase in the area of a covering, it is possible to use signal repeaters that will allow to increase covering radius.

Feature of system is that, only one is only necessary main the computer from which there is a distribution of commands. If there is an access to the computer through network, then it is possible to be connected to it from any device and to make adjustment of devices and collection of information.

Development of the system of management of latches in thermal point is given as an example of automation in the system of housing. Each latch is equipped with the electric drive and connected to the general relay of management. For detection of leaks pressure sensors before and after latches and also temperature sensors for control of temperature condition are installed. In system indication of work of a latch is reflected information in real time on its status. The relay of management works in two modes - is closed and is open. The system works in two modes, automatic adjustment, on in advance developed algorithm and manual remote control. 
In the drawing the developed managing configurations for automatic and manual control are provided by a latch, data of the information management system are shown by the equipment.

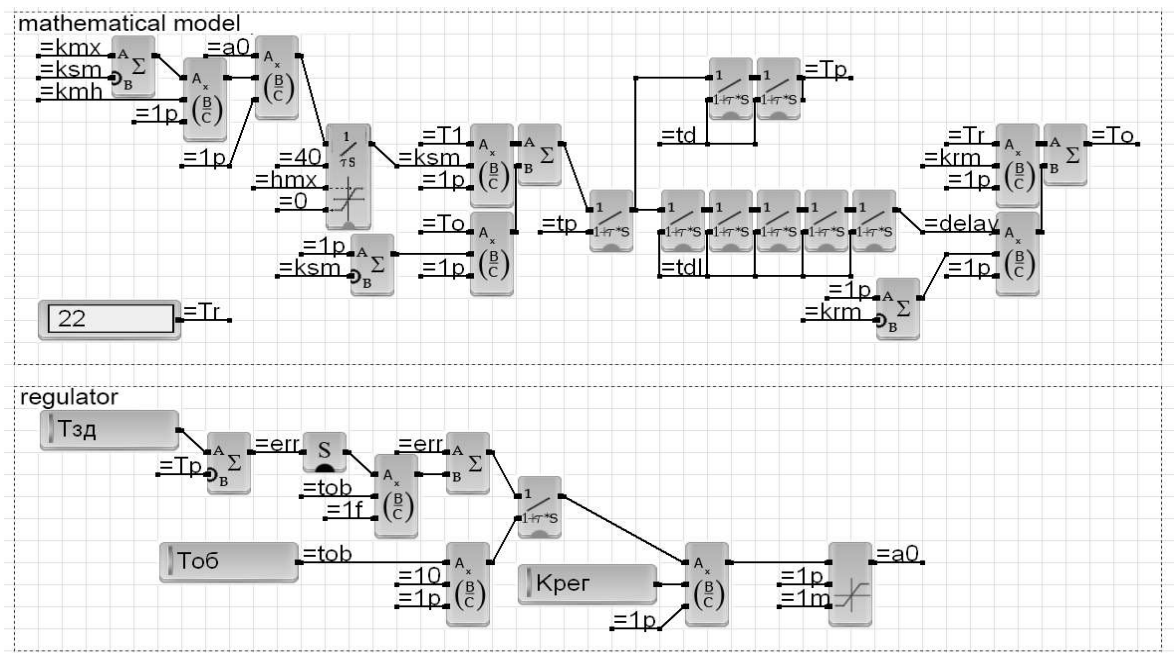

Figure 4: Managing Configurations for a Latch:

$\mathrm{kmx}$-information of pressure of the manometer before a latch, ksm - information of temperature condition before a latch, kmh -indication of operating condition of a latch, $1 \mathrm{p}$ - information transfer on the control panel on pressure, $\mathrm{a} 0$ - adjustment of extent of opening of a latch depending on pressure, $\mathrm{hmx}$ - minimum admissible temperature on the return pipeline, T1 - Temperature of supply of hot water, heating in the house, T0 Temperature of supply of energy resource in a trass, tp - regulation on the standard program, td - data transmission on the module of control of a program runtime, $\mathrm{Tp}$ - accounting of an expense of the consumed energy, krm - collection of data on errors in work, $\mathrm{Tr}$ - the number of the connected modules to one control bar.

The mathematical model is applied to creation of commands of interrelation between the module of management, the relay of management and pressure sensors and temperatures and also indications of their functioning.

The regulator is used for automatic and manual control by system in the parameters set in advance and also data transmissions on the managing module.

In the drawing the scheme of the automated thermal point is submitted.

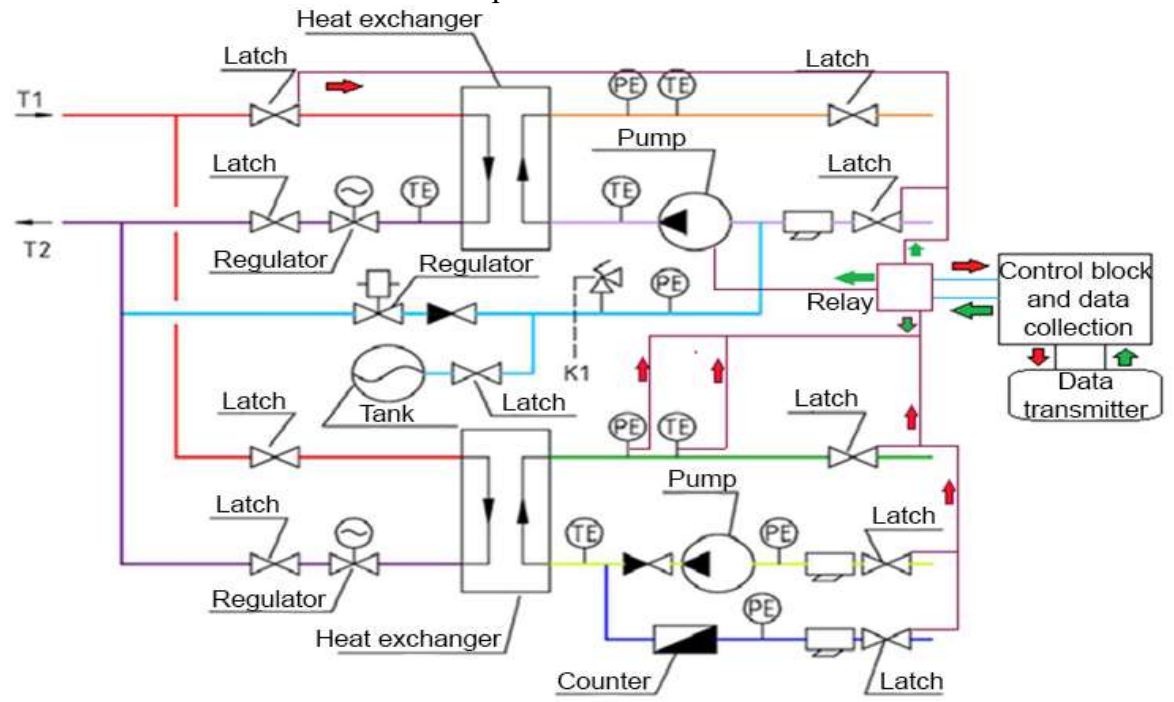

Figure 5: Scheme of the Automated Thermal Point:

$\mathrm{T} 1$ - maximum temperature load, $\mathrm{T} 2$ - maximum heating load, $\mathrm{PE}$ - pressure sensors, $\mathrm{TE}$ - temperature sensors.

Latches are equipped with the electric drive for remote opening and closing. Information from metering devices is read out and the computer is constantly transferred in office by means of the GSM module on main. Also perhaps remote switching of operation modes of pumps and their complete stop in need of shutdown of a water supply system.

\section{Conclusions}

Creation of system of the automated remote control of blocks of switches in apartments and on the central strut of hot water supply in the cellar requires purchase of cranes with the drive and accomplishment of their connection to the relay of management. The developed standard configurations of the different equipment taking into account assignment are 
loaded into the relay of management. The radio transmitter which will organize a communication channel is installed and performs permanent interaction through network with the computer host. Pulse counters which transfer data on a consumption of energy resources join the managing relay (fig.).

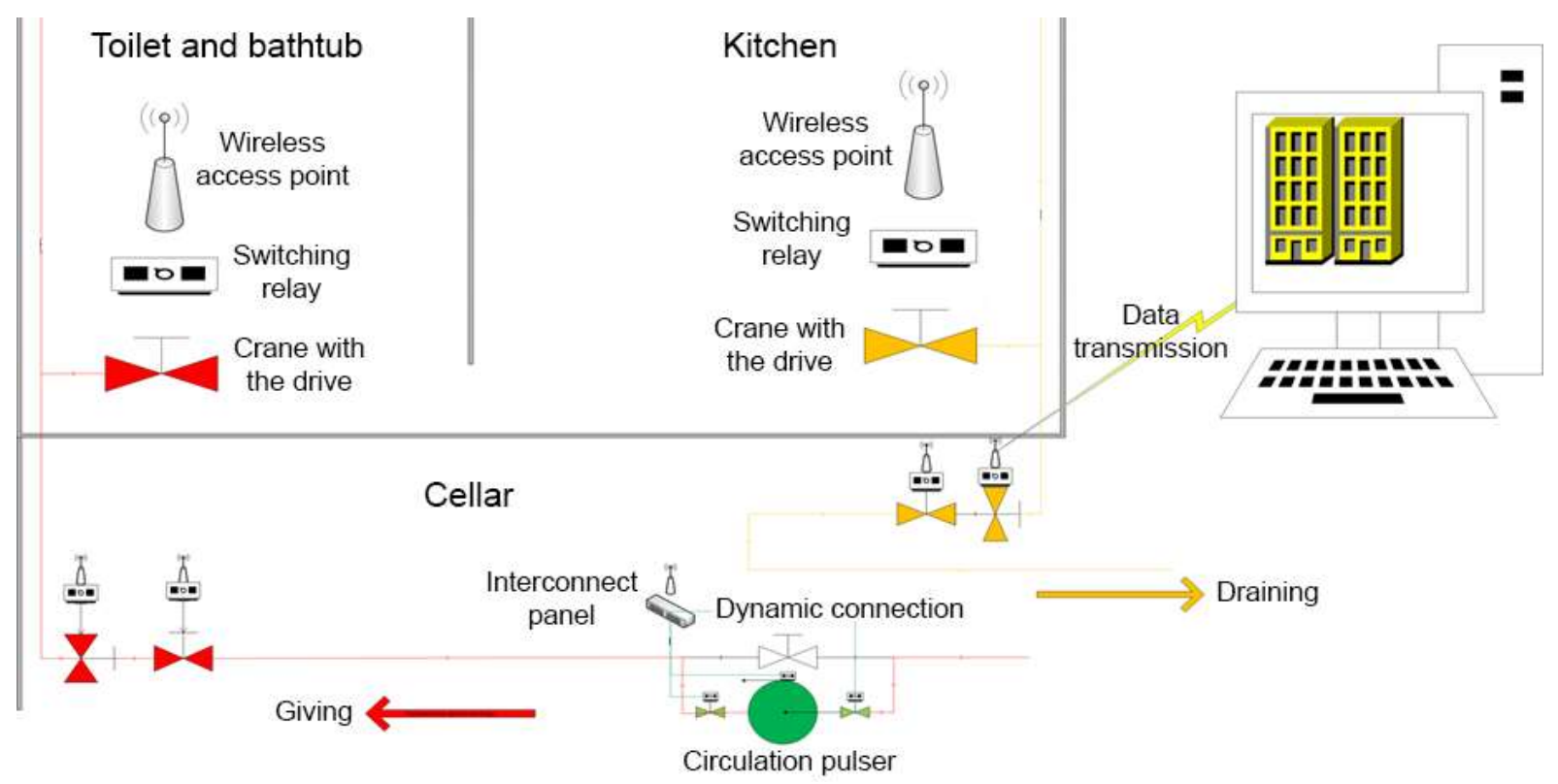

Figure 6: Scheme of Automatic Remote Control of Cranes and Pumps

All information on an expense of resources on each device arrives on the computer host and is displayed on the website in a numerical and graphic type. The website can be configured, adding or removing necessary functionality, it is also possible to manage inline tunings of system in general.

\section{Acknowledgements}

The work is performed according to the Russian Government Program of Competitive Growth of Kazan Federal University.

\section{References}

[1] Karamyshev A.N., Analysis of universal methodologies of process management of industrial enterprises// Astra Salvensis. - 2017. - Vol.2017, Is.. - P.159-166.

[2] Makhmutov I.I, Murtazin I.A, Isavnin A.G. Karamyshev A.N., Methods and models of outsourcing// International Journal of Economic Perspectives. - 2017. - Vol.11, Is.3. - P.1620-1632.

[3] Karimov S.A., Sibaeva G.R., Eremina I.I., Karamyshev A.N, Method of introducing the multidimensional concept of authorization SAP BW// Journal of Advanced Research in Dynamical and Control Systems - 10 13 Special Issue, - P. $536-540$.

[4] Eremina, Irina I.; Gazizov, Ilnaz F., Accounting and analysis of inventories of materials and production of companies// DILEMAS CONTEMPORANEOS-EDUCACION POLITICA Y VALORES - Issue 6.

[5] Makhmutov I.I., Isavnin A.G., Karamyshev A.N.,Sych S.A., Classification approach in determination of knowledge in context of organization// Academy of Strategic Management Journal, - Volume 15, - Issue Special Issue, -1 January - 2016, - P. 40-46.

[6] Farkhoutdinov I.I., Isavnin A.G., Restructuring of Russian enterprises on basis of industrial outsourcing// Astra Salvensis, - Volume 2017, - 2017, - P. 331-337.

[7] Ishmuradova I.I., Lysanov D.M.,Motova A.V., Mathematical formulation of the problem of the routing of school transport // International Journal of Mechanical and Production Engineering Research and Development (IJMPERD) - 2018 Vol. 8. - Special Issue 6. - P. 1085-1092.

[8] Miftakhova A.R., R.sibaeva, G.,Lysanov D.M., Karamyshev A.N. A development of an online monitoring system of the public transport// Astra Salvensis, Supplement No. 2/2017. - P. 545-556.

[9] Ishmuradova I.I., Ishmuradova A.M. Stochastic modeling of economic activity of costs on Innovation of the organization of the Republic of Tatarstan, in the formation ofbusiness processes // RevistaPublicando - 2017. Vol. 4 - No 12. (1) -P. - 545-559.

[10] Ishmuradova I.I., Karameshev A.N., Sultanova A.M., Ishmuradova, A.M.. Design and development of the information system for the support of human resources// International Journal of Engineering \& Technology, 7 (3.27) - $2018-$ P. $-550-555$. 